\title{
A Perspective on the Role of Catheter Ablation in the Management of Tachyarrhythmias
}

\author{
FRED MORADY
}

From the Division of Cardiology, Department of Internal Medicine, University of Michigan Medical Center, Ann Arbor, Michigan

\section{Introduction}

The first clinical application of a catheter ablation technique was to create complete atrioventricular (AV) block by the transcatheter delivery of a direct-current shock to the AV junction in patients with supraventricular tachycardia refractory to pharmacologic therapy. ${ }^{1,2}$ This was followed by attempts at catheter ablation of ventricular tachycardia (VT) foci, accessory pathways, and atrial tachycardia foci. The purpose of this article is to provide a perspective on the current role of these catheter ablation techniques in the management of patients with tachyarrhythmias.

\section{General Comments}

\section{Requirements for Physicians Performing Catheter Ablation}

Physicians who perform catheter ablation procedures should be competent in all areas of clinical electrophysiology. This requires a minimum of one year of training devoted to clinical electrophysiology. The physician must be able to determine accurately tachycardia mechanisms, to identify and localize accessory pathways, and to map the exit sites of ventricular tachycardia. In addition to technical competency in these areas, the physician should be experienced with the use of pharmacologic therapy, devices such as the automatic implantable cardioverter/defibrillator, and the surgical approaches to the therapy of tachycardias. The interests of the patient are best

Address for reprints: Fred Morady, M.D., Division of Cardiology, University Hospital, 1500 East Medical Center Drive, UH BI F245-0022, Ann Arbor, MI 48109-0022.

Received February 3, 1987; accepted February 13, 1987. served by physicians who are experienced not only with catheter ablation techniques, but also with the other available forms of nonpharmacologic therapy. Only physicians who are familiar with the pros and cons of all forms of nonpharmacologic therapy are able to select the best form of therapy for a given patient.

\section{Resources Necessary for Performing Catheter Ablation}

Certain resources must be available for performing detailed electrophysiologic studies in the initial evaluation of potential catheter ablation candidates.

A cardiothoracic surgeon and an operating room equipped for cardiopulmonary bypass should be immediately available in the event of cardiac tamponade. Although the risk of perforation of a myocardial structure is small with the catheter ablation techniques currently in use, it is nevertheless possible that a catheter-related problem may result in a misdirected shock and myocardial or coronary sinus perforation. Surgical back-up, therefore, must be available.

In addition, hospitals in which catheter ablation procedures are performed should have the capability for continuous electrocardiographic monitoring in the post-ablation period. Patients must be carefully observed for the occurrence of new arrhythmias related to the intracardiac shocks.

\section{Catheter Ablation of the AV Junction}

\section{Efficacy and Risk}

The Percutaneous Mapping and Ablation Registry has accumulated data on the efficacy and 
ery of shocks to the wall of the right atrium or in the right atrial appendage. ${ }^{12,13}$ Experience with this technique is preliminary and any conclusions regarding its role in the management of patients who have atrial tachycardias would be premature.

\section{Expectations for the Future}

Development of a catheter technique which reliably modifies AV conduction without creating high degree AV block would result in resolution of symptomatic tachycardias without the need for a permanent pacemaker. Modification of the AV junction has been difficult to achieve with direct-current shocks, but it is possible that better techniques will be developed with the use of laser or radiofrequency. Eventually, catheter "modification" (as opposed to "ablation") may become a reasonable alternative to pharmacologic therapy, instead of a last resort, in patients who have symptomatic supraventricular tachycardias.

\section{References}

1. Scheinman MM, Morady F, Hess DS, et al. Catheter-induced ablation of the atrioventricular junction to control refractory supraventricular arrhythmias. JAMA 1982; 248:851.

2. Gallagher JJ, Svenson RH, Kasell JH, et al. Catheter technique for closed-chest ablation of the atrioventricular conduction system. N Engl J Med 1982; 306:194.

3. Ross DL, Johnson DC, Denniss AR, et al. Curative surgery for atrioventricular junctional ("AV nodal") reentrant tachycardia. J Am Coll Cardiol 1985; 6:1383.

4. Evans GT Jr, Scheinman MM, and the Executive Committee of the Registry. Catheter ablation of ventricular tachycardia foci: A report of the Percutaneous Cardiac Mapping and Ablation Registry. Circulation 1986; 74 (Supp II):1835.

5. Fontaine G, Tonet JL, Frank R, et al. La fulguration endocavitaire. Une nouvelle methode de traitement des troubles du rhythme? Ann Cardiol Angéiol 1984; 33:543.

6. Klein H, Trappe HJ, Frank G, et al. Is fulguration of ventricular tachycardia really a new promising therapeutic approach? PACE 1986; 9:95.

7. Belhassen B, Miller HI, Geller E, et al. Transcatheter electrical shock ablation of ventricular tachycardia. J Am Coll Cardiol 1986; 7:1347.
At this point, it seems unlikely that catheter ablation will ever assume a major role in the treatment of patients with VT who often have diffuse myocardial disease and multiple potential VT foci. Furthermore, in many cases there may not be an actual VT "focus," but instead a large area of macroreentry. It therefore may be unrealistic to expect that any technique which produces small and discrete lesions will be effective in a large proportion of patients who have recurrent VT.

Preliminary experience suggests that catheter ablation of posteroseptal and right free-wall accessory pathways may have an acceptable risk/benefit ratio. More accurate mapping techniques will undoubtedly be important for improving results of catheter ablation of right-sided accessory pathways. It remains to be determined whether a safe and effective catheter technique for ablating left free-wall accessory pathways can be developed.

8. Morady F, Scheinman MM, DiCarlo LA Jr, et al. Catheter ablation of ventricular tachycardia with intracardiac shocks: Results in thirty-three patients. Circulation 1987; 75:1037.

9. Fisher JD, Brodman R, Kim SG, et al. Attempted nonsurgical electrical ablation of accessory pathways via the coronary sinus in the Wolff-Parkinson-White syndrome. J Am Coll Cardiol 1984; $4: 685$.

10. Warin JF, Haissaguerre M, Belhassen B, et al. Electrical catheter ablation of accessory pathways: Beneficial effects using a direct approach in 10 patients. Circulation 1986; 74 (Supp II):1544.

11. Morady F, Scheinman MM, Winston SA, et al. Efficacy and safety of transcatheter ablation of posteroseptal accessory pathways. Circulation 1985; 72:170.

12. Gillette PC, Wampler DG, Garson A Jr, et al. Treatment of atrial automatic tachycardia by ablation procedures. J Am Coll Cardiol 1985; 6:405.

13. Davis J, Scheinman MM, Ruder MA, et al. Ablation of cardiac tissues by an electrode catheter technique for treatment of ectopic supraventricular tachycardia in adults. Circulation 1986; 74:1044. 